\title{
Sergio Solmi, Saggi di letteratura francese, T. II. Saggio su Rimbaud, la luna di Laforgue e altri scritti
}

\section{Mario Richter}

\section{(2) OpenEdition}

1 Journals

\section{Edizione digitale}

URL: http://journals.openedition.org/studifrancesi/7671

DOI: 10.4000/studifrancesi.7671

ISSN: 2421-5856

\section{Editore}

Rosenberg \& Sellier

\section{Edizione cartacea}

Data di pubblicazione: 1 décembre 2009

Paginazione: 656

ISSN: 0039-2944

\section{Notizia bibliografica digitale}

Mario Richter, «Sergio Solmi, Saggi di letteratura francese, T. II. Saggio su Rimbaud, la luna di Laforgue e altri scritti», Studi Francesi [Online], 159 (LIII | III) | 2009, online dal, consultato il 08 janvier 2021. URL: http://journals.openedition.org/studifrancesi/7671 ; DOI: https://doi.org/ERREUR PDO dans / localdata/www-bin/Core/Core/Db/Db.class.php L.34 : SQLSTATE[HY000] [2006] MySQL server has gone away

Questo documento è stato generato automaticamente il 8 janvier 2021.

\section{(c) (i) $\odot$}

Studi Francesi è distribuita con Licenza Creative Commons Attribuzione - Non commerciale - Non opere derivate 4.0 Internazionale. 


\title{
Sergio Solmi, Saggi di letteratura francese, T. II. Saggio su Rimbaud, la luna di Laforgue e altri scritti
}

\author{
Mario Richter
}

\section{NOTIZIA}

SERGIO SOLMI, Saggi di letteratura francese, T. II. Saggio su Rimbaud, la luna di Laforgue e altri scritti, a cura di Giovanni PACCHIANO, Adelphi Edizioni, 2009, pp. 587.

Il quarto volume delle Opere di Sergio Solmi dedicato alla letteratura francese (della quale nell'intero corso della sua attività culturale il poeta e saggista fu cultore sensibile, acuto e attento) si compone di due tomi. Del primo abbiamo già dato breve informazione in questa rassegna (LI, III, 2007, p. 686). Questo secondo tomo (anch'esso confortato da un'abbondante e precisa annotazione dovuta al curatore Giovanni Pacchiano) riveste un particolare interesse per noi perché ripropone, fra il resto, alla lettura due opere fondamentali come il Saggio su Rimbaud (apparso per la prima volta nel 1974) e La luna di Laforgue (1976). Il Saggio su Rimbaud, risultato di un paziente lavoro di informazione, ha un valore documentario di primissimo piano per capire l'incidenza che Rimbaud ebbe sull'intera poesia moderna e, in particolare, su quella italiana, della quale Solmi fu senz'altro uno dei maggiori protagonisti. Il Saggio è infatti scritto con pacatezza critica, con informazione sicura, ma anche con profonda passione. È nato dal sentimento che, come confessa il critico, Rimbaud costituisce per lui "una spina nel cuore" ed è nel contempo sostenuto da un pensiero altamente fecondo, dal quale il libro trae la sua densità e il suo spessore al di là del gusto e della finezza di lettura. Il pensiero è il seguente: «Che cosa sarebbe scrivere d'arte, di critica, se non fosse, in pari tempo, scrivere della vita?» (sulle implicazioni culturali di quest'opera, mi sia consentito di rinviare al mio lontano commento Il "Saggio su Rimbaud" di Sergio Solmi. Considerazioni intorno a un 'mito', in "L'Approdo Letterario", XXII, 1976, pp. 31-47). La Luna di Laforgue fu un libro vivo e stimolante fin dal suo primo apparire, presentando 
tre magistrali saggi su Laforgue, appunto, su Jarry e su Apollinaire. Ma questo secondo tomo non si esaurisce qui. Le altre sezioni di cui si compone offrono al lettore la possibilità di leggere o rileggere un gran numero di scritti critici che Solmi pubblicò in varie sedi e che oggi non sono sempre di facile reperibilità. I «Saggi» raccolgono i seguenti studi: Poesia francese 1950; Roussel ancora; La morte di Raymond Roussel; Appunti sulla critica di Leo Spitzer; Jude Stéfan; Gaspard de la Nuit; Una poesia di Verlaine (si tratta di "Poème saturnien" in Parallèlement); Una esperienza fondamentale di René Daumal. Le Letture riuniscono i seguenti scritti d'occasione: Lo stile di Michelet; Il mito di Rimbaud, Rimbaud e $i$ comprachicos; Anecdotiques di Apollinaire, Armen Lubin, Le Voyeur; La Jalousie; Bonjour tristesse; Les Mots di Sartre; Lettere di Daumal; Antonin Artaud. La sezione «Varie» presenta quattro interventi: Suzanne et le Pacifique di Jean Giraudoux; Ready made; Le défaut d'être; Originalità (lamento di un 'ci-devant'). Il tomo si conclude con una serie di scritti raccolti sotto una sezione intitolata «Scritti inediti e sparsi» (Arthur Rimbaud; Frammento 1926; Centenario di Rimbaud; Paul Verlaine; Poesia negra; René Guénon; Il mito Radiguet; Moralità leggendarie di Laforgue) e con un bel saggio del curatore dedicato al significato degli interessi francesi di Solmi (Camminare sull'arcobaleno). 